\title{
Ciência e confessionalidade: condição possível para a construção da Ciência da Religião
}

\author{
Science and confessionality: possible condition for the construction of the
}

\author{
Study of Religion
}

\section{Resumo}

Antonio de Oliveira Siqueira ${ }^{1}$ siqueira.antonio@terra.com.br

Este artigo pretende discutir a possibilidade da construção da Ciência da Religião com a devida isenção e distanciamento, independentemente do credo daquele que produz o conhecimento, levando-se em consideração principalmente a discussão dos argumentos acerca do que é a epistemologia da Ciência da Religião, a impureza acadêmica na visão de Antônio Flávio Pierucci, os comentários e considerações de Marcelo Camurça, o processo de construção da ciência e o distanciamento científico.

Palavras-chave: Distanciamento científico. Imparcialidade. Ciência da Religião.

\begin{abstract}
This article intends to discuss the possibility of constructing the Study of Religion with due exemption and distance, regardless of the creed of the one who produces the knowledge, taking into account mainly the discussion of the arguments about what is the epistemology of the Study of Religion, academic impurity in the vision of Antônio Flávio Pierucci, the comments and considerations of Marcelo Camurça, the process of building science and scientific distancing.
\end{abstract}

Keywords: Scientific distancing. Impartiality. Study of Religion.

\section{Introdução}

A construção de uma Ciência, e aqui em especial da Ciência da Religião, mais próxima do que se pode considerar como ideal, está relacionada a um conjunto de fatores próprios daquilo que se pode entender como ciência e, também, ligada às particularidades que cercam a própria Ciência da Religião.

Os tratamentos das questões tangentes aos estudos da religião apresentam uma especificidade mais delicada que é o posicionamento do autor frente ao tema e sua

1 Doutorando em Ciência da Religião (PUC-SP - 2016). Mestre em Tecnologia Ambiental (IPT 2005). Pós-graduado em Formação Humana em Aconselhamento - Counseling (FAVI - 2015). Pós-graduado em Perícia e Auditoria Ambiental (IPT - 2005). Especializado em Economia e Meio Ambiente (UFPR - 2016). Especializado em Counseling (IATES - 2009). Graduação em Tecnologia de Gerenciamento Ambiental Industrial (FATEC Oswaldo Cruz - 2003). Professor pós-graduação e graduação da Universidade São Judas Tadeu. Professor de pós-graduação do Instituto IATES. 
bagagem de crenças e experiências vividas, quer ele seja ateu ou crente, ou ainda como crente, aderente ou adverso ao objeto de estudo. Essas condições, por sua vez, podem contaminar os resultados das pesquisas, considerando a possibilidade da precária isenção ou parcialidade ante a matéria de estudo.

Diante disso, que é o distanciamento do cientista da religião em relação ao objeto de estudo, cuja finalidade é alcançar o melhor resultado possível da pesquisa, será realizada uma discussão teórica e, adicionalmente, serão elaboradas análises da argumentação e contra argumentação de dois autores importantes da área em questão, por meio de seus textos, cuja essência das alegações estão ligadas ao distanciamento do objeto de estudo e à possibilidade da construção da Ciência da Religião.

Assim, para a finalidade pretendida, serão utilizados dois autores e seus textos, de acordo com o que segue:

a) Antônio Flávio Pierucci

“Interesses religiosos dos sociólogos da religião” (Pierucci, 1999a).

“Sociologia da religião: área impuramente acadêmica” (Pierucci, 1999b).

b) Marcelo Camurça

“Da "boa” e da "má vontade” para com a religião nos cientistas sociais da religião brasileiros” (Camurça, 2001).

\section{A epistemologia da Ciência da Religião}

Tendo como objeto de estudo a religião, a Ciência da Religião, inicialmente, precisa ser considerada como uma "disciplina autônoma que deve ocupar um lugar institucional específico no mundo acadêmico” (Usarski, 2006, p. 9), cujo objetivo é:

[...]fazer um inventário, o mais abrangente possível, de fatos reais do mundo religioso, um entendimento histórico do surgimento e desenvolvimento de religiões particulares, uma identificação e seus contornos mútuos, e a investigação de suas inter-relações com as outras áreas da vida” (Usarski, 2006, p. 126).

Um modelo decorrente, que pode auxiliar na organização do pensamento para uma avaliação mais criteriosa do sistema religioso, que produz, portanto, uma maior facilidade de interpretações pode ser, por exemplo, o estabelecido por Charles Glock, 
que supõe um conjunto com cinco dimensões: ritualista, da fé, da experiência religiosa, do conhecimento e da ética (Usarski, 2006, p. 73).

Segundo Jensen (2013, p. 172), a epistemologia geral pode ser adequadamente aplicada à Ciência da Religião e há alguns pontos que são merecedores de ênfase em relação à epistemologia geral, que são:

a) A questão da natureza dos dados, os modos de raciocínio inferencial, as consequências do relativismo;

b) Razões de argumentação e justificação, a questão das “virtudes epistêmicas”, e o problema do “conhecimento dos inobserváveis”.

Como base, a epistemologia, segundo Jensen (2013, p. 172), “é a teoria do conhecimento, do que este consiste, de como podemos obtê-lo e como podemos defender e justificar o nosso conhecimento”.

No que se refere à sua função, a epistemologia consiste em "mostrar que a atividade científica é um produto humano e, por isso, uma realidade sócio-histórica” e que, "por definição, a atividade científica encontra-se em estado de constante inacabamento”. (Japiassu, 1975, p. 26).

As principais abordagens da epistemologia são divididas em empirismo, racionalismo e construtivismo, cada qual portadora de características muito peculiares e que podem ser utilizadas de acordo com as várias necessidades de cada autor de seus estudos, mediante uma avaliação criteriosa. Quanto aos resultados, os mais compensadores virão de combinações que forneçam descrições tão abrangentes quanto possíveis dos fenômenos investigados (Jensen, 2013, p. 172-181).

Acerca dos métodos e procedimentos de pesquisa, continua o autor, precisam ser "virtuosos no sentido de que a objetividade, imparcialidade, honestidade, reflexividade e autocrítica serão os alicerces sobre os quais se deve construir” (Jensen, 2013, p. 186187), tendo como grande desafio que: “o 'não visível' deve ser traduzido em questões que sejam epistemicamente acessíveis”. (Jensen, 2013, p. 188).

Em detrimento de todos os esforços empreendidos para se produzir verdades sobre o campo de estudo em questão, “no sentido de dar coerência e consistência aos estudos realizados nesse novo campo disciplinar, verifica-se ainda a ausência de clareza 
epistemológica”, incorrendo em inseguranças quanto ao método e ao objeto (Teixeira, 2013, p. 175).

Por conta disso, e fazendo parte do procedimento de contextualização e do processo construtivo desse saber acerca do objeto denominado religião, serão apresentados mais adiante dois autores, cuja contribuição é relevante e permanece atual nas discussões, Antônio Flávio Pierucci e Marcelo Ayres Camurça Lima, onde o segundo escreveu um comentário (Camurça, 2001) acerca dos textos publicados pelo primeiro (Pierucci, 1999a; 1999b).

Por outras palavras, segundo o que nos apresenta Japiassu (1975, p. 28):

A epistemologia lança o desafio da comprovação concreta daquilo que é tido como científico: se pensamos fazer ciência, devemos saber fundamentar essa crença; se acreditamos que outras pessoas não fazem ciência, precisamos comprovar tal negação.

\section{A visão de Pierucci}

Nascido em 28 de agosto de 1944 em Altinópolis, interior do Estado de São Paulo, a cerca de 330 km da capital, Antônio Flávio Pierucci foi um sociólogo de “corte weberiano” (Mariano, 2013, p. 7), cuja atuação em especial ocorreu no campo da sociologia da religião, tendo se sobressaído em sua trajetória três objetos de estudo: a produção teórica de Max Weber (1864-1920), o perfil do voto conservador em São Paulo e o enfraquecimento do catolicismo coincidindo com a ascensão das denominações neopentecostais.

Entrou aos 11 anos no Seminário Menor da Diocese de Ribeirão Preto. Graduouse em filosofia no Seminário Central da Arquidiocese de São Paulo (1962-1964) e depois em teologia na PUC-SP (1965-1968). Em seguida, entre os anos de 1968 e 1970, apesar de não ter concluído, cursou o doutorado em teologia dogmática na Pontifícia Universidade Gregoriana de Roma (Mariano, 2013, p. 8).

Graduou-se em filosofia (1973) e obteve os títulos de Mestre em Ciências Sociais (1977, com “Igreja Católica e reprodução humana no Brasil”), pela Pontifícia Universidade Católica de São Paulo (PUC-SP); Doutor em Sociologia (1985, com “Democracia, Igreja e Voto: o envolvimento do clero católico nas eleições de 1982”) e Livre-docente (2001, com “Desencantamento do mundo: os passos do conceito em Max 
Weber”) pela Universidade de São Paulo, onde foi professor titular e chefe do Departamento de Sociologia até o seu falecimento aos 67 anos, em São Paulo em 8 de junho de 2012, após ter construído uma carreira significativa, repleta de artigos e com livros importantes. (Pierucci, 2017)

Segundo Mariano (2013, p. 15):

Flávio fazia questão de publicizar (sic) sua posição, tanto no ofício sociológico quanto no papel de cidadão brasileiro com visibilidade pública, a favor da democracia, das liberdades modernas, da laicidade do Estado e da secularização da esfera jurídica.

Assim, diante desse histórico, passaremos a avaliar dois de seus escritos, não por outro motivo, senão a polêmica e mal-estar produzidos à época e que até os dias de hoje ainda provocam reações.

O primeiro deles foi publicado em 1977 como resultado do Congresso Globalização e Religião promovido pelo Programa de Pós-Graduação em Antropologia Social da Universidade Federal do Rio Grande do Sul, ocorrido entre os dias 6 e 8 de novembro de 1996.

O segundo texto é o décimo capítulo do segundo volume de uma coleção da ANPOCS, O que ler na Ciência Social brasileira (1970-1995), que reúne análises reflexivas sobre Antropologia, Sociologia e Ciências Políticas, cujo ano de lançamento foi 1999, cerca de dois anos após o primeiro texto do autor que será analisado.

\subsection{Primeiro texto: “Interesses religiosos dos sociólogos da religião”}

O autor inicia seu texto pedindo desculpas, pois pretendia, segundo suas próprias palavras, produzir "algum deslocamento do foco das atenções de todos” (Pierucci, 1999a, p. 249), pois queria tratar das questões que envolviam os cientistas e pesquisadores, considerando os conteúdos que havia entrado em contato advindo desses intelectuais e produtores do conhecimento voltados para a sociologia da religião.

Inicialmente entende que há um avanço interessante nos estudos relacionados à religião e demais temas tangentes e que "não para de crescer o número dos intelectualmente interessados em religião, em formas religiosas, em formas de vida religiosas”. (Pierucci, 1999a, p. 249). 
Apesar disso, há duas questões apresentadas pelo autor, que produziam, por assim dizer, um certo desconforto no modo como eram abordadas: o campo religioso e a secularização.

\subsubsection{O campo religioso e seus limites}

O primeiro aspecto questiona e produz uma reflexão de onde começa e onde termina o tal campo religioso, sempre ancorado no pensamento de Bourdieu, que propôs uma "sociologia da sociologia", constituída de um olhar crítico sobre a formação do sociólogo como avaliador e detentor de um discurso de verdade sobre o mundo social, existindo uma imprecisão importante de limitação entre a ciência e religião, cujo efeito pode produzir resultados inadequados, ou por suas palavras:

Penso que um pouco mais de Bourdieu, do modo como Bourdieu olha para a religião, um pouco mais daquele rigor científico radicalmente desencantado, que disseca a coisa enquanto critica a própria disciplina que a observa, faria muito bem a todos nós. (Pierucci, 1999a, p. 251).

Mais adiante, em uma palestra ministrada por Bourdieu, o autor indica que havia descoberto um tema que julgava ser “da maior importância” para ser avaliado no contexto da religião enquanto fenômeno por analisar:

[...] qual a fronteira da instituição religiosa, daquela que organizando a crença no religioso organiza também a crença na instituição que organiza a crença? Como se definem as fronteiras de uma organização religiosa? E quem as define? Os deputados constituintes? Os tribunais pressionados pelas partes? Quando um comportamento é religioso e quando não é, ou quando deixa de ser? (Pierucci, 1999a, p. 251).

Dessa forma, continua seu debate por conta da possibilidade de contaminação dos resultados das pesquisas, da construção do conhecimento científico quando pertencente de um universo de crença, se caracterizado como má fé, pois as fronteiras entre ciência e fé ficaram sem os definidos contornos, que são necessários para uma abordagem correta e isenta.

Demonstrando muita preocupação, Pierucci (1999a, p. 255) explicita dois fatos que geram esse sentimento: que muitos pesquisadores brasileiros estão ligados à alguma crença religiosa e que boa parte dos resultados das pesquisas terminam por enaltecer a religião. Aparecendo, portanto, como resultado dessa evidência o que foi denominado como “jogo duplo” e da “dupla vantagem”. 
Para solução desse problema, o sociólogo sugere que é imperioso assumir a condição de pertencimento ao campo religioso, evitando-se a criação de obstáculos para a objetivação.

Antes mesmo de terminar esse primeiro grande argumento, explica os motivos de sua insatisfação ou, mais ainda, as causas para esse "recado":

É que anda muito na moda, agora fazer sociologia da religião para elogiar a religião, mostrar os benefícios que ela faz às pessoas, sobretudo das camadas despossuídas, à sociedade como um todo, à própria democracia. Hoje não é raro, muito pelo contrário, é cada vez mais frequente ouvir de "sociólogos da religião" (sem fé ou sem cerimônia?) que a religião confere empowerment às pessoas porque fortalece o associativismo voluntário, que a religião aumenta a auto-estima dos indivíduos das camadas mais desprotegidas porque motiva a abandonar comportamentos indesejáveis, como o alcoolismo, o homossexualismo, a dependência de drogas etc. (só falta falar que a religião liberta os pobres da preguiça), que a participação religiosa incrementa a participação civil, enfim, que a religião produz subjetividades ativas”. (Pierucci, 1999a, p. 256-257).

E em sintonia com esses motivos, Pierucci, como que contestando as alegações desses supostos sociólogos sem isenção e com parcialidades, lembra que:

[...] toda religião é uma forma histórica de dominação; que toda religião ética é, basicamente, repressão das nossas melhores energias vitais; e que a sociologia da religião só é possível porque tem na crítica moderna da religião sua condição pós-tradicional de possibilidade enquanto ciência. Enquanto ciência moderna, enfatizo. (Pierucci, 1999a, p. 257).

\subsubsection{A secularização como desenraizamento dos indivíduos}

Com relação a este segundo aspecto abordado pelo autor, o mesmo defende que secularização e intensificação da mobilização religiosa são condições que podem ser vistas como paralelas e que não são opostas.

A secularização, por suas palavras, "tem que ser vista como desenraizamento dos indivíduos e, só enquanto tal, dessacralização da cultura”, que significa produzir indivíduos livres e prontos para duvidar de sua pertença religiosa, criando um ambiente de deserção da fé, potencializando aos indivíduos “experimentar tantas outras quebras de lealdade”. (Pierucci, 1999a, p. 258).

Mas para se chegar a esse ponto, haveria a necessidade de uma maior liberdade religiosa por meio de uma pluralidade mais consistente, fato que não se percebe na condição brasileira, onde se perpetua o cristianismo dos católicos, protestantes e 
espíritas, sendo as demais religiões insipientes. O Brasil, segundo Pierucci (1999a, p. 261) “é ainda tão pobre, tão magro, tão limitadinho em matéria de variedade religiosa”.

\subsection{Segundo artigo: “Sociologia da Religião: área impuramente acadêmica”}

O texto, “Sociologia da Religião: área impuramente acadêmica”, é uma análise da produção acadêmica brasileira sobre a sociologia da religião, especialmente abrangendo o período entre 1970 e 1995, que foi divulgado pela ANPOCS na publicação O que ler na Ciência Social brasileira (1970-1995).

Sob a mesma sombra da desconfiança de que as fronteiras entre ciência e fé ficaram sem os definidos contornos, o “sociólogo de corte weberiano” (Mariano, 2013, p. 7) abre o texto em questão indicando que há uma grande dificuldade para se separar a ciência da religião, a fé da razão. Afirma ele que:

Mais de uma vez já me dei o trabalho de chamar publicamente a atenção para os riscos implicados na maciça presença entre nós, quem sabe excessiva ou quem sabe excessivamente tolerada, de "interesses religiosos" mobilizados não muito às claras e com escassa reflexividade por sociólogos amantíssimos do valor da religião, amorosíssimos para com as mais diversas formas de religiosidade, ao mesmo tempo, desconfiados do que quer que se proponha ou se almeje como método científico, rigor científico, validade científica. (Pierucci, 1999b, p. 238-239).

Dessa maneira, sob a denominação de "impuramente acadêmicos” (Pierucci, 1999b, p. 239), que o autor indica a forma de desvio de conduta de autores que, a pretexto de um desamor pela ciência pura, cuja intenção é burlar a regra para atingir resultados anteriormente denominado como “jogo duplo" e da “dupla vantagem”. (Pierucci, 1999a, p. 255).

Vale, entretanto, uma observação que é resultado da própria afirmação de Flávio Pierucci (1999b, p. 244): “a retrospectiva que resultará deste ensaio será não apenas inevitavelmente subjetiva, mas também assumidamente pessoal e perspectivista”.

Afirma além disso, um pouco mais adiante no texto, ainda na introdução, que “as ciências sociais da religião no Brasil nunca foram, nem jamais chegaram a ser uma área puramente acadêmica”, e que "continuamos todos a integrar ainda hoje uma área academicamente impura”. (Pierucci, 1999b, p. 245). 
É diante dessa premissa que o autor segue “pondo cartas na mesa”, evidenciando a situação de promiscuidade que permeiam os estudos da religião no Brasil, pois há um contingente relevante de interessados em fazer ciência, pertencentes ao campo religioso, “religiosamente orientados” e com “interesses religiosos”. (Pierucci, 1999a, p. 246).

Segundo o autor, existem três categorias de produtores da ciência, os religiosos praticantes e/ou profissionais da religião que praticam a ciência em alto nível; os Religiosos praticantes e/ou profissionais da religião que não sabem separar ciência e religião; e os Profissionais da ciência, completamente isentos e com clareza de limites entre razão e fé.

A seguir, faz uma retrospectiva da sociologia da religião, cujos títulos são: “Anos 50 e 60: uma sociologia religiosa do declínio da religião hegemônica” (Pierucci, 1999a, p. 254) e “Anos 70: o retorno dos religiosos (e do sagrado) à academia” (Pierucci, 1999a, p. 262).

Por fim, após esse processo descritivo da sociologia ao longo do tempo, segundo sua perspectiva, entra a fase de sua conclusão, quando retoma com o mesmo título utilizado no texto analisado anteriormente, quando tratou do campo religioso: “Fronteiras borradas e jogo duplo”. (Pierucci, 1999a, p. 250; Pierucci, 1999b, p. 271).

O conteúdo, por sua vez, segue de maneira muito semelhante ao teor encontrado na parte do texto anterior com o mesmo título, que é a falta de contornos claros limitando o processo de pesquisa e construção da ciência, o que é consequência da parcialidade conferida pela pertença religiosa do indivíduo.

\section{A contra argumentação de Camurça}

Menos de dois anos após a referida publicação do segundo texto de Pierucci, que é alvo da análise, Marcelo Camurça tem um texto seu publicado na Revista Religião e Sociedade, cujo objetivo era comentar os textos indicados.

A propósito, Marcelo Ayres Camurça Lima, segundo o que está publicado na Plataforma Lattes, possui graduação em História pela Universidade Federal do Ceará (1983), mestrado em Sociologia pela Universidade Federal do Ceará (1987), doutorado em Antropologia Social pelo Museu Nacional da Universidade Federal do Rio de 
Janeiro (1994) e realizou seu pós-doutorado na Ecole Pratique des Hautes Etudes/Sorbonne, Session Sciences Religieuses (2009). É Professor Titular da Universidade Federal de Juiz de Fora, no Departamento de Ciência da Religião, atuando no Programa de Pós-Graduação em Ciência da Religião e no Programa de PósGraduação em Ciências Sociais (Camurça, 2017).

Há que se destacar também uma vasta produção científica, de acordo com o que consta no seu currículo na Plataforma Lattes e, de acordo com a mesma base de dados, atualmente está vinculado a dois projetos de pesquisa (Camurça, 2017):

- Entre o campo religioso e o espaço público: fronteiras conceituais e empíricas das religiões no brasil contemporâneo

Contribuir para a elaboração de uma teoria de maior fôlego, indo ao encontro do desafio proposto por Paula Montero, capaz de propor em novas bases as relações entre cultura e sociedade, pois, para a autora o campo de estudos da religião se encontra fracionado e incapaz de construir uma problemática que associe uma leitura fina dos processos de significação à análise das determinações mais estruturais que orientam a ação social.

- Dimensões das Religiões no Brasil: porosidades, competições e presença pública Busca produzir um panorama geral das principais religiões brasileiras com inserção social: catolicismo, protestantismo, kardecismo, religiões afrobrasileiras e "nova era". Visa discutir a presença das religiões no espaço público, sua relação com o Estado enquanto instância reguladora de sua presença plural e do relacionamento destas entre si e com outras instituições públicas e privadas.

\subsection{O texto de Camurça}

O texto de Camurça foi apresentado à Revista Religião e Sociedade em janeiro de 2001 e publicado em abril do mesmo ano, cujo título, sugestivamente foi:

Da "boa" e da "má vontade" para com a religião nos cientistas sociais da religião brasileiros. (Comentários a propósito do balanço realizado por Antônio Flávio Pierucci sobre a produção acadêmica da sociologia da religião no Brasil, nos últimos 25 anos). (Camurça, 2001, p. 67). 
Ao longo da leitura desse texto, é possível observar o cuidado com que o autor produziu sua argumentação, utilizando critérios comparativos e ferramentas de metodologia, de tal sorte que favorece a apresentação na conclusão de sua discordância dos argumentos utilizados por Pierucci "pelo menos no nível em que as coloca" (Camurça, 2001, p. 84).

Marcelo Camurça esclarece os dois aspectos motivadores para sua atitude de produzir seus comentários sobre os posicionamentos e opiniões expressadas por Flávio Pierucci, quais sejam (Camurça, 2001, p. 67-68): o balanço do autor, tendo como alvo central a revista Religião e Sociedade, incluindo os artigos, editoriais, entrevistas, os participantes do Conselho de Redação, pois os considera com significativos problemas científicos; e as ideias veiculadas por Pierucci acerca do campo religioso.

Em seguida esclarece os argumentos e problemática levantados pelo autor, objetivando uma melhor compreensão do leitor que não manteve contato com os textos, cuja essência está na ideia de que a área da sociologia da religião se constitui como “impuramente acadêmica”, sendo, portanto, desprovida de confiabilidade científica.

A partir de então, Camurça (2001, p. 71-72) produz a problematização, considerando que Pierucci é crítico da perda do rigor acadêmico pelos sociólogos da religião por força de parcialidade; e daí seguem suas indagações (Camurça, 2001, p. 7182): [...] "de toda a complexidade e transformações que se operaram nas ciências sociais e na sua aplicação ao fenômeno religioso nestes últimos 25 anos, seria este o grande dilema que se avulta na área?”; Rigor ou “patrulhamento científico”?; “Corte epistemológico” ou “fronteiras borradas”?; “Desperdício acadêmico” ou questão de “mudança de paradigmas”?; Da “crença dos sociólogos das crenças” ao “senso comum douto” em Pierre Bourdieu.

Após toda essa desconstrução da argumentação dos conceitos de Pierucci exprimidos em seus escritos e a construção de uma avaliação pausada, Camurça faz um encerramento desse bloco analítico com uma alegação antecedente à conclusão, com vistas ao comentário de Pierucci sobre "sociologia da sociologia da religião”.

Segundo Camurça (2001, p. 82), esse balanço de Pierucci sobre os últimos 25 anos dos estudos sociológicos da religião no Brasil, "resulta um tanto unilateral, pois 
centrando seu foco prioritariamente nos ditos 'interesses religiosos' dos sociólogos da religião, termina por desconsiderar outras facetas da mesma ordem”.

Assim, constrói uma argumentação sob a perspectiva da parcialidade que Pierucci adota em seu balanço, apoiando-se em autores por ele reconhecidos e indicando que o interesse dele estava mais centrado em desqualificar a religião, mais que avaliar algum outro aspecto ou, ainda pelas duras palavras de Camurça, “implicando em uma análise desfavorável da religião sob a capa de um discurso científico e objetivo” (Camurça, 2001, p. 82).

Ainda, ao final dessa alegação, exprime sua convicção sobre a ineficácia do fatiamento do campo de estudo por meio do entendimento de Paula Montero, como uma forte contraposição ao posicionamento de “corte weberiano” (Mariano, 2013, p. 7), sendo indispensável a renovação de conceitos e teorias, à medida que os objetos se modificam com o tempo, neste caso, em especial a religião e a modernidade.

Por fim, Marcelo Camurça, apesar de tratar o texto como uma reação ao conteúdo de Pierucci, em sua conclusão indica não querer fazer uma defesa corporativa da sociologia da religião e, tampouco, “tomar as dores”. Enfatiza seu respeito às contribuições do autor e, em especial, ao argumento acerca das deficiências dos estudos sobre a religião, além de valorizar a contribuição para a reflexão "que cresce e se alimenta dos dissensos e controvérsias”. (Camurça, 2001, p.84).

Há, porém, um recado bem claro sobre a forma com que Flávio Pierucci, equivocadamente, apresentou seus argumentos sem o rigor acadêmico e o distanciamento científico, em detrimento de recriminar a ausência de ciência nos estudos da religião.

\section{A Ciência da Religião e seus construtores}

Ao longo deste artigo nos preocupamos em estabelecer argumentos com vistas a identificação da possibilidade de construção de um saber sobre a religião, mesmo que por pesquisadores com alguma pertença religiosa.

Inicialmente, tratamos das bases epistemológicas da Ciência da Religião, momento que identificamos a condição de que precisamos considerá-la como 
independente, em detrimento das contribuições que recebe e produz para as demais, com um objetivo bastante particular e que o distingue de tantos outros processos de produção de conhecimento, cujo objeto deve ser tratado com o devido distanciamento.

Para isso, se presume que os métodos e procedimentos de pesquisa precisam ter “objetividade, imparcialidade, honestidade, reflexividade e autocrítica” (Jensen, 2013, p. 186-187), tendo como grande desafio que “o 'não visível' deve ser traduzido em questões que sejam epistemicamente acessíveis” (Jensen, 2013, p. 188), mesmo existindo dúvidas e inseguranças, que, aliás, mais que um problema, são as condições que podem produzir a melhoria contínua do conhecimento.

A dúvida, então, pode ser vista como grande propulsora do novo para a construção do conhecimento, ou, dito de outra maneira, “a novidade, ainda que não rejeitada, está sob suspeita” e "podemos questionar o caminho antigo, e então, ao olhar em torno de nós, descobrir que é o caminho reto e modo certo, e assim andar sobre ele”. (Bacon, 2015, p. 73-74).

É pelo viés do questionamento, enquanto construtor da ciência, que Libanio (2014, p. 35) indica que o “segredo do pensar” é que “alguém aprenderá a pensar à medida que souber fazer-se perguntas sobre seu pensamento”. Decorrente dessa afirmação, o autor sugere três atitudes que possibilitam o pensar de uma forma mais apropriada e, como não podia deixar de ser, em forma de perguntas (Libanio, 2015, p. 40-42): o que diz a realidade? (Distância: momento objetivo); o que me diz a realidade? (Proximidade: momento subjetivo); o que a realidade me faz dizer? (Comunicação: momento intersubjetivo)

E o autor continua sua argumentação acerca do pensamento como forma de construção da ciência, sempre pontuando a necessidade da alimentação daquele que se interessa por esse caminho por meio da apropriação do conhecimento advindo do grande hábito da leitura e construção de textos, um nutrindo o outro, como uma retroalimentação infinita e fecunda, corroborando, portanto, com o pensamento de um dos ensaios de Bacon, De estudos, (Bacon, 2015, p. 149), quando afirma que "homens astuciosos desprezam estudos, os homens simples os admiram e os homens sábios os usam”, ou ainda quando estabelece que “a leitura torna um homem pleno; o diálogo, um homem vivo; e o escrever um homem exato”. 
Seguindo, Libanio (2015, p. 48) praticamente encerra seu capítulo Aprender a pensar com uma afirmação importante: “aprender a pensar é pensar livre com o único compromisso com a verdade”, de forma que será possível a libertação de condicionantes “ideológicas, fundamentalistas, dogmáticas”.

Assim, a construção da ciência precisa ser da maneira mais isenta possível, em especial quando se trata de fé e razão, de onde podemos trazer como um exemplo a figura de São Tomás de Aquino, que, nas condições de seu tempo iniciou um diálogo com o pensamento árabe e hebreu, buscando demonstrar com fatos aquilo que ele mesmo costumava afirmar: que era necessário receber a verdade, viesse de onde viesse, sem preconceitos.

Em paralelo e com vistas ao auxílio da estruturação do pensamento para a finalidade da construção do conhecimento, entende-se como lógica a construção das premissas apresentadas por Michael Löwi (1998, p. 17), as quais estão baseadas na doutrina da neutralidade axiológica do saber, conforme as concepções positivistas no domínio das ciências sociais, ou melhor: a sociedade é regida por leis naturais; a sociedade pode ser epistemologicamente assimilada pela natureza e ser estudada pelos mesmos métodos e processos empregados pelas ciências da natureza; as ciências da sociedade, tal como as da natureza, precisam limitar-se à observação e à explicação causal dos fenômenos, de forma objetiva, neutra, livre de julgamentos de valor ou ideologias, descartando previamente todas as pré-noções e preconceitos.

Apesar da posição apresentada, entende-se como importante a apresentação do argumento de Hilton Japiassu, que entende não existir uma ciência isenta, não sendo possível a objetividade absoluta, considerando que essa imagem do mundo elaborada será sempre uma interpretação e profundamente marcada pela sua condição cultural (Japiassu, 1975, p. 9-18).

Ainda, segundo o mesmo autor, apesar de considerar como princípio que a atividade científica precisa estar afastada do senso comum, de percepções instantâneas, especulações, simplismos, opiniões e subjetividades, ainda assim entende que se trata de “atividade humana e social como qualquer outra” e que está “impregnada de ideologias e juízos de valor, de argumentos de autoridade, de dogmatismos ingênuos, chegando 
mesmo a ser desenvolvida em instituições fechadas, verdadeiras 'seitas' científicas, com suas linguagens próprias, para não dizer ‘dialetos’”. (Japiassu, 1975, p. 24-25).

No que tange aos pensamentos produzidos por Pierucci e Camurça, destacamos a seguir uma série de considerações que podem ser analisadas como relevantes e que invalidam parcialmente a argumentação de que a sociologia da religião é uma "área impuramente acadêmica” e que é possível a construção de ciência por meio de indivíduos que confessam e praticam alguma fé.

Em primeiro lugar, mesmo estabelecendo uma série bem extensa de discordâncias sobre os argumentos de Pierucci, Camurça concorda com a condição de que existem deficiências importantes permeando a área das ciências sociais da religião e que os cuidados devem ser sempre estabelecidos como forma de preservar o verdadeiro sentido de sua existência.

No que se refere às diferenças entre eles, Camurça, apesar de entender como produtiva a crítica feita por Pierucci, não concorda com a forma que este apresenta seu pensamento, construído sem o rigor acadêmico que deveria ter e com generalizações imprudentes e, até arriscando afirmar, criticando a ausência de diplomacia ao tratar de um tema que atinge aos pares, coisa que Camurça soube bem fazer em seu texto.

Pierucci, portanto, não poderia ter elaborado seus textos da forma com que fez para abordar a construção de ciência, deixando de lado o rigor acadêmico e o distanciamento científico, que são elementos estruturantes para se fazer ciência.

Para evidenciar essas observações e invalidar parcialmente sua argumentação, além daquilo que foi devidamente apresentado por Marcelo Camurça, podemos destacar o que segue.

No texto "Interesses religiosos dos sociólogos da religião", o autor, praticamente, utilizou apenas uma de suas obras (Pierucci, 1996) e somente uma do autor Pierre Bourdieu (Bourdieu, 1990).

Nesse mesmo texto há como referência mais quatro autores, Camargo (1973), Kepel (1991), Thomas (1985) e Max Weber (1992), todos citados tão-somente em uma única oportunidade. 
O autor pediu a "quebra de lealdade" de forma inadequada, até pelo fato disso significar perda da honra, do compromisso, falta da sinceridade, franqueza ou honestidade, o que não combina com a ciência.

Os dois textos estão carregados de linguajar coloquial, impregnado de cinismos e adjetivos, tendo ainda utilizado de 81 estrangeirismos nos dois textos e nas mais diversas línguas.

Foi possível perceber um clima de parcialidade e subjetivismo em suas abordagens, sem se apoiar em condições que favoreçam a construção do saber.

São dois textos com posicionamentos análogos, apesar da diferença de quase dois anos entre eles, caindo por terra a possibilidade de um pensamento fugidio ou de momento, como se pudesse ter caráter pouco ponderado.

Ele, Pierucci, apesar de cobrar isso (pelas suas próprias palavras: “Tem que assumir"; Pierucci, 1999b, p. 277), não declara sua pertença religiosa, de tal sorte que, por vezes, é como se estivesse na posição de combate às religiões hegemônicas e suas manifestações.

\section{Considerações finais}

Por fim, naquilo que foi proposto acerca da discussão da possibilidade da construção de uma ciência da religião com a devida isenção e distanciamento, independentemente do credo daquele que produz o conhecimento, não há oposição entre a fé e a construção da ciência, podendo esta última ser viabilizada por quem quer que seja, bastando o respeito à algumas condições.

Para isso, dois pilares são indispensáveis, a honestidade do autor e o respeito ao método, como forma de se aproximar o máximo possível dos melhores resultados sem contaminação.

Em consonância com essas condições apresentadas, para a realização da ciência da religião sem os ditos "interesses religiosos" ou que não se manifeste de forma "impuramente acadêmica”, o que se pode esperar é a participação das pessoas envolvidas com a ciência com conhecimento, sem preconceitos e com uma boa-fé, ou, 
como apresenta Japiassu (1975, p. 100), “a ciência não funda uma ética, mas é fundada por uma ética”.

Não se pode deixar de considerar, especialmente no que se concerne à Ciência da Religião, que a austeridade nos interesses, métodos e conceitos sobre "religião" exigem dos pesquisadores dessa área um ideal muitas vezes não observado nas demais áreas e que culpar os "interessados" seria "ignorar o caráter cooperativo da tarefa de elevar o estatuto científico de uma disciplina”. (Cruz, 2013, p. 47).

Temos assim, algumas premissas, dentre as quais podemos destacar: que a ciência busca por meio de um método a verdade, mas, à medida que o tempo passa essa verdade pode ter sido construída de maneira inadequada; que, consciente ou inconscientemente essa verdade pode estar contaminada; a objetividade absoluta é uma miragem; a atividade científica está em constante inacabamento; que existem métodos e procedimentos elaborados com a finalidade de conduzir ao melhor resultado possível.

Portanto, diante do que foi possível apresentar ao longo do texto e das premissas indicadas, podemos entender que a construção da ciência de forma satisfatória é possível, especialmente pelo seu caráter impermanente, mesmo que seja por pesquisadores que professam alguma fé, sendo entretanto necessária a adoção de uma postura individual e coletiva fundada em bases ética sólidas, sem dispensar em paralelo a adoção de procedimentos de avaliação crítica com vistas ao aperfeiçoamento dos resultados para o benefício da sociedade.

\section{Referências}

BACON, Francis. Ensaios. Tradução de Alan Niel Ditchfield. São Paulo: Folha de São Paulo, 2015. Coleção Grandes nomes do pensamento, v.13. 176 p.

BOURDIEU, Pierre. Sociólogos da crença e crença de sociólogos. In: Idem, 1990, Coisas ditas. São Paulo: Brasiliense, 1990, p. 108-113.

CAMARGO, Cândido Procópio Ferreira de. Católicos, protestantes, espíritas. Petrópolis: Vozes, 1973.

CAMURÇA, Marcelo Ayres. Currículo do sistema currículo Lattes. [Brasília], 30 abr. 2017. 
$<$ http://buscatextual.cnpq.br/buscatextual/visualizacv.do?id=K4786439H3>. Acesso em: 30 abr. 2017.

Da "boa” e da "má vontade” para com a religião nos cientistas sociais da religião brasileiros. Revista Religião e Sociedade, Rio de Janeiro, n. 1, vol. 21, p. 67-86, abr., 2001.

CRUZ, Eduardo R. Estatuto epistemológico da Ciência da Religião. In: PASSOS, João Décio; USARSKI, Frank. Compêndio de Ciência da Religião. São Paulo: Paulinas e Paulos, 2013, p. 37-49.

JAPIASSU, Hilton. O mito da neutralidade científica. Rio de Janeiro: Imago, 1975. 187 p.

JENSEN, Jeppe Sinding. "Introdução: temas epistemológicos para o estudo da religião". Tradução de Eduardo Rodrigues da Cruz. In: REVER - Revista de Estudos da Religião, São Paulo, ano 13, n. 02, p. 171-191, jul./dez. 2013.

KEPEL, Gilles. La revanche de Dieu. Paris: Seuil, 1991.

LIBANIO, João Batista. Introdução à vida intelectual. 5. ed. São Paulo: Loyola, 2014. 307 p.

LÖWY, Michael. As aventuras de Karl Marx contra o Barão de Münchhausen: marxismo e positivismo na sociologia do conhecimento. 6. ed. Tradução de Juarez Guimarães e Suzanne Felicie Léwy. São Paulo: Cortez, 1998. 220 p.

MARIANO, Ricardo. Antônio Flávio Pierucci: sociólogo materialista da religião. RBCS - Revista Brasileira de Ciências Sociais, São Paulo, vol. 28, n. 81, p. 7-16, 2013.

PIERUCCI, Antônio Flávio. In: Wikipédia: a enciclopédia livre. Wikimedia, 2017. Disponível em: <https://pt.wikipedia.org/wiki/Ant\%C3\%B4nio_Fl\%C3\%A1vio_Pierucci>. Acesso em: 30 abr. 2017.

. Liberdade de cultos na sociedade de serviços: em defesa do consumidor religioso. In: PIERUCCI, Antônio Flávio; PRANDI, Reginaldo. A realidade social das religiões no Brasil: religião, sociedade e política. São Paulo: Hucitec, 1996. 
Interesses religiosos dos sociólogos da religião. In: ORO, Ari Pedro; STEIL, Carlos Alberto (Orgs.). Globalização e religião. 2.ed. Petrópolis: Vozes, 1999a, p. 249-262.

Sociologia da religião: área impuramente acadêmica. In: MICELI, S. (Org.). O que ler na Ciência Social brasileira (1970-1995). Sociologia. vol. II. São Paulo/Brasília: Editora Sumaré/ANPOCS/CAPES, 1999b, p. 237-286.

TEIXEIRA, Faustino. Ciência da Religião e Teologia. In: PASSOS, João Décio; USARSKI, Frank. Compêndio de Ciência da Religião. São Paulo: Paulinas e Paulos, 2013, p. 175-183.

THOMAS, Keith. Religion and the decline of magic: studies in popular beliefs in sixteenth and seventeenth century England. Londres: Penguin Books, 1985.

USARSKI, Frank. Constituintes da Ciência da Religião: cinco ensaios em prol de uma disciplina autônoma. São Paulo: Paulinas, 2006. 140 p.

WEBER, Max. The protestant ethic and the spirit of capitalism. Londres: Rutledge, 1992. 